\title{
ICO Mechanism Essence and Key Concept
}

\author{
I. Lukasevich* \\ Department of Corporate Finance \& Corporate management \\ Financial University under the Government of the RF \\ Moscow, Russian \\ lukas1963@yandex.ru
}

\begin{abstract}
The study is focused on ICO, a new method of finance attraction to business by primary placement of digital financial instruments. The study provides the analysis of ICO advantages and disadvantages compared to the traditional financial instruments, as well as the prospects, restrictions and challenges related to application of the digital financial instruments. The conclusions on the abilities, restrictions and trends of application of digital instruments for financing business, by the real economy sector enterprises as well, taking into account the peculiarities of the Russian economy and legislation. It is shown that the main challenges of the digital financial instruments application are of economic character; they are caused by the lack of reasonable methods of asset evaluation and shortage of objective information.
\end{abstract}

Keywords-Digital financial instruments; Blockchain; Initial coin offering (ICO); Business financing; Corporate finance

\section{INTRODUCTION}

Development in the area of IT and telecommunications over the recent decade has led to the appearance of such innovations as cryptocurrency (coins) and digital financial instruments and assets (tokens) based on the blockchain technology. Hence, application of the latter for business financing is of main interest in the corporate finance area.

In the area of digital economy the way of financial sources attraction as initial coins offering, ICO, has recently become very popular.

The analysis shows, that this mechanism can help to implement both, the traditional (issue of capital and raising funds), and a number of alternative methods of financial resources attraction (venture financing, crowdfunding, etc.). Thus, this article is devoted to the analysis of their benefits, applicability, restrictions and prospects.

\section{DISCUSSION}

\section{A. The ICO Mechanism}

ICO, in general, is a process of initial placement of digital financial assets, the so-called tokens.

Technically, the token is an entry in the blockchain register, that allows using it for implementation of the corresponding rights or requirements depending on the programming method and function $[1,2,3]$.

Economic/financial essence of tokens depends on their programmed function [3]. Practically, they can simultaneously do the following:

\author{
T. Kozenkova \\ Department of Management \\ Academy of Management and Business Administration \\ Moscow, Russian \\ kozenkovat@mail.ru
}

- have the purchasing power and serve as a payment instrument in the ecosystem of the given project or even beyond its limits (cryptocurrency);

- play a role of the financial instrument (as a rule, the alternative of a share, bond, deposit or warrant), and be freely traded on trading pits and exchange services;

- certify the rights of ownership (equity tokens) or investor's loan (credit coins) in any project/entity (i.e. serve as credits and bond certificates);

- certify the rights for purchase of a certain amount of services, goods/property (the so-called app-coins or application coins);

- be a kind of award for some actions, etc.

The ICO mechanism can be represented in the simplified form below.

Investing the funds into the enterprise or the project on the blockchain technology basis, the investors provide the financial resources in exchange for the tokens to be further used as the internal project/business currency (i.e. new cryptocurrency), exchanged into the fiat money, other cryptocurrency, goods and services, or traded as digital financial assets on stock exchanges.

As a rule, an investor has to register a special electronic wallet on the certain platform to purchase the tokens or it has to use the online stock exchanges or exchange services according to the rules set forth by the emitent.

The enterprise attracting funds, in its turn, issues the tokens using the blockchain technology, sets the price of placement in monetary terms and sells the tokens for cryptocurrency or fiat money to investors under the certain terms.

Technically, the tokens are issued by adding the transaction into a blockchain, providing their quantity, description and assigning the unique identification code. Each token placed in the course of ICO, corresponds to the undeletable and unchangeable record in a blockchain that ensures its easy exchange and preservation. When issued, the tokens can be sent to any e-wallet in the blockchain system.

Later, the tokens can be traded on special trading pits or online services where they can be exchanged into cryptocurrency or fiat money, ensuring free circulation, so that anyone can purchase them at the market price. 


\section{B. Comparative Analysis: ICO vs Traditional Financial Instruments}

In some publications and sources of references, the ICO process is sometimes identified with the initial public offering (IPO or PPO), obviously, due to the similar abbreviations [1, 2, 3]. Due to a number of reasons, the most important of them are given below, such approach, however, cannot be considered correct:

- complexity of economic relations and property rights that can be expressed by tokens;

- common properties and differences between the tokens and the other instruments of funds attraction, including crowdfunding and venture financing;

- features of issue and placement process, etc. them.

From our point of view, it would be reasonable to focus on

Similar to IPO/PPO, the token can express the economic property relations and provide the right for a certain share of the company assets. In this case, the token is officially a 'digital' or virtual share and it can be freely traded on particular stock exchanges.

The analysis reveals that many ICO, performed or initiated recently, offer the equity participation to the investors [4].

However, it should be noted that as opposed to the shares, the rights offered by the token are neither set forth in the legislation of the most countries, nor warranted by anyone, they are legally null and void, and can differ significantly from the traditional rights.

In this regard, in most cases possession of such token does not offer any right to participate in the company management, in shareholders meetings, in taking solutions, etc., which is a disadvantage for investors, and the advantage for the emitent, since the latter preserves the whole control over its business.

Despite the fact that participation in ICO project can offer the dividend payment or other payments (e.g. for validation of operations, i.e. mining), they are, in fact, a sign of good will or a part of development of emitent's business reputation. To be fair, it should be pointed out that the dividend payment can be easily programmed in a smart contract and performed automatically regardless of the emitent's will. Moreover, the ICO participants can obtain the award in diverse forms, e.g. for mining, activity in social networks, for 'likes', reposts, feedbacks, commentaries, delegation of rights, providing the domestic computing capacities, purchase of goods and services of the relative project, etc.

Since the most tokens are not secured by any property, the investor can hardly expect the liquidation payments if business collapses.

Thus, the investors can obtain the award only in case of token cost increase if the project succeeds and they are liquid, or in case of later IPO process execution. In the latter case the tokens are a kind of digital warrants - the financial instruments that give the right for the purchase of some amount of shares at the predetermined price (which is less, as a rule) in case of initial or secondary emission in future.

This thesis can be proved by the above-mentioned recent and widely known preliminary ICO process of the well-known messenger Telegram [5].

As already noted, the tokens can be issued in a form of appcoins to be used for purchase of goods and services of the company (e.g. paying for taxi, gigabytes on file servers, purchase of goods of certain manufacturers, etc.). In this case, they are a kind of a gift and bonus cards of famous retailers, loyalty programs of airlines and railways, bonus programs of banks, etc. It can be easily seen, that they do not offer the equity rights to the investor.

The IPO object is a joint-stock company in the given jurisdiction, performing its activity at the traditional markets of goods and services, under control of the board of directors and hired managers.

The decentralized organization (DAO) functioning in a blockchain system without centralized control can be the ICO object.

Unlike $I P O / P P O$, where the main participants are several tens of qualified institutional investors, the investors in ICO can be thousands or even hundreds of thousands of individuals, incompetent in financial area or business area of the emitent. Their participation can be caused by non-economic reasons, e.g. by a wish to support their favorite internet-service, by obtaining any status or privileges (games, dating sites, social networks, etc.), by emotional satisfaction, etc. Hence, ICO execution allows collecting of multiple loyal consumers, directly interested in business success and facilitating its development before the stage of development and production of the certain products and services.

In our opinion, the most important differences between IPO and ICO are in the emission procedure. Since the IPO procedure is strictly regulated by the state and financial regulators, the time and money costs for its preparation are rather high (several years and hundreds of thousands, or millions of US dollars, respectively). Multiple financial, legal, audit and consulting companies participate in its preparation and execution. As a result, the investors are protected by law, acquire information, since main parameters and financial indicators of the emitent's business are available, and as soon as the emission is completed, they are carefully monitored and controlled by many professional market players. All investors of the company, in their turn, are also known or can be easily identified and they have to provide information about them. Therefore, such method of funds attraction is suitable for large or mature medium-sized enterprises with the stable business, and completely inappropriate for startups, small companies or sole entrepreneurs.

It seems that use of the promising technologies (blockchain) and lack of legal regulation and its restrictions are the main competitive advantages of ICO. As a result, this procedure takes from several minutes (or even seconds) up to one month without significant emission costs (it is estimated on average from 10 to 20 thousand US dollars), which makes this financing method available for anyone, including the sole 
entrepreneurs. The anonymous investors can also participate in ICO without specifying their identity, status or location, in theory.

A wide number of participants (most of them cannot be referred to qualified specialists), similar investment targets, poor regulation or lack of regulation, and Internet services orientation confirm a close interaction between ICO and crowdfunding. The main difference between them now is that the investors in crowdfunding are not anonymous, and fiat money is used. Besides, due to multifunctional nature of the token, ICO often allows creating of the project or business ecosystem and attracting its customers at the same time.

Now, development of these financing instruments runs in parallel, however, in the nearest future we can expect their convergence and gradual turn of crowdfunding to the blockchain technologies.

The analogy can also be made between ICO and venture financing. Both instruments can be used to finance the startups and the projects of the high risk. However, there are several major differences between them.

Similar to $I P O$, in venture financing the private enterprise or a joint stock company in the given jurisdiction is finances, in opposite to ICO where often the distributed/decentralized organization $(D A O)$, functioning in a blockchain system is financed. Venture financing is based on the principle of portfolio diversification, and its participants are the experienced businessmen and highly-qualified investors, creating special funds for such purposes. The term of divestiture is from three to five years and over, hence, the investors, as a rule, participate in the project and provide the consulting and other services.

Compared to that, ICO is a more convenient model, since the investor can exit the project at any moment, if its tokens are liquid, or automatically, when the set parameters are fulfilled (e.g. the profit value or token value). Project implementation monitoring can be simplified and the management costs can be reduced, respectively.

As for the crowdfunding, the gradual convergence of ICO and venture financing can also be expected.

Thus, ICO is a multifunctional, fast, highly-technological and rather flexible method of finance attraction, available to any participant of business activity, in theory.

However, the investors that purchase tokens are not immune to the risks, intentional fraud, hacker attacks, they do not have any warrants or legal protection.

The emitents, in their turn, in case of non-fulfillment of KYC (KnowYourCustomer) and AML (Anti-MoneyLaundering) principles, i.e. anonymous nature of ICO procedure, can obtain the unwanted investors, including criminal and terroristic organizations, and be subject to close attention and investigation by the law enforcement officials.

\section{CONCLUSION}

Despite some advantages, ICO and its use for financing of technological companies and projects is associated with some problems. Usually the problems of legal character, including some of the above-mentioned are put forward.

But experts support the view that apart from legal insecurity of investors that will be solved sooner or later, they face the other problem - the capital efficiency estimate, and the prospects of token cost growth in case of transactions at stock exchange.

In case of use of debt instruments or debt tokens, the problem of evaluating the creditworthiness of the entity arises, since this entity is present as the Internet-page only, it does not have any real assets, and proper security/pledge.

In our opinion the main economic ground of both problems is that many ICO-projects are startups or due to their peculiarities they are poorly monetized. In the first, and particularly in the second cases they are unable to generate the cash flows, therefore, it is difficult to apply existing methods to their financial evaluation [6].

At the first sight, ICO procedure execution by the companies of the real economy sector is free from the abovementioned problems. In this case, however, they face the other problems, such as the volumes of the investments involves, arrangement of further token circulation, their converting and implementation of the rights concerned with them.

It is not also obvious, how the processes that are effective in blockchain, perform in the framework of centralized national economies, since their operation and management contradict to the basic principles of blockchain. While in many countries, and in Russia as well, some companies of the real economy sector performed ICO (e.g. farmers' cooperative LavkaLavka, 'Kolionovo' farm, UAZ factory and other) [7], now, this financing method can hardly be recommended for the projects which are outside this system and not related to blockchain technologies.

Finally, it should be reminded that cryptocurrency and tokens are illegal payment instruments in the Russian Federation and other countries. Thus, token placement for attraction of real financing can be performed only for fiat money.

Any economy is based on the certain product and its value, despite of the beauty of its name. Therefore, the modern financial science, and its 'Corporate finance' chapter, in particular, faces the challenges that require fast response and can possible lead to the radical review of the current basic concepts, the appearance of new evaluation methods and patterns according to the complexity of the set tasks.

The adaptation of the theoretical base of the corporate finance, financial and investment management, the capital market to new reality is the demanding task.

Future of these scientific disciplines and the way of digital and real economy development mostly depends from successful solution of these tasks. 


\section{REFERENCES}

[1] P. Vigna and M. Casey, The Era of Cryptocurrency. How bitcoin and blockchain are challenging the global economic order, Picador St. Martins Press, New York, 2016.

[2] M. Swan, Blockchain: Blue Print of New Economy Scheme of the new economy, O'Really Media, Sebastopol, CA 95472, 2015.

[3] D. Tapscott, Blockchain Revolution: How the Technology Behind Bitcoin Is Changing Money, Business, and the World. Pinguin Random House LLC, New York, 2016.
[4] White paper of Monetha ICO project. URL: https://ico.monetha.io/Monetha_WP.pdf.

[5] White paper of ICO by popular messenger Telegram. URL: https://drive.google.com/file/d/1oaKoJDWvhtlvtQEuqxgfkUHcI5np1t5 Q.

[6] https://www.bloomberg.com/news/articles/2017-10-23/only-one-in-10tokens-is-in-use-following-initial-coin-offerings.

[7] URL: http://www.forbes.ru/tehnologii/343603-ferma-kolionovo-vmoskovskoy-oblasti-privlekla-na-ipo-na-blokcheyne-500-000. 